\title{
El escepticismo científico en la construcción de la información financiera: Estado del conocimiento
}

Scientific skepticism in the construction of financial information: State of the art

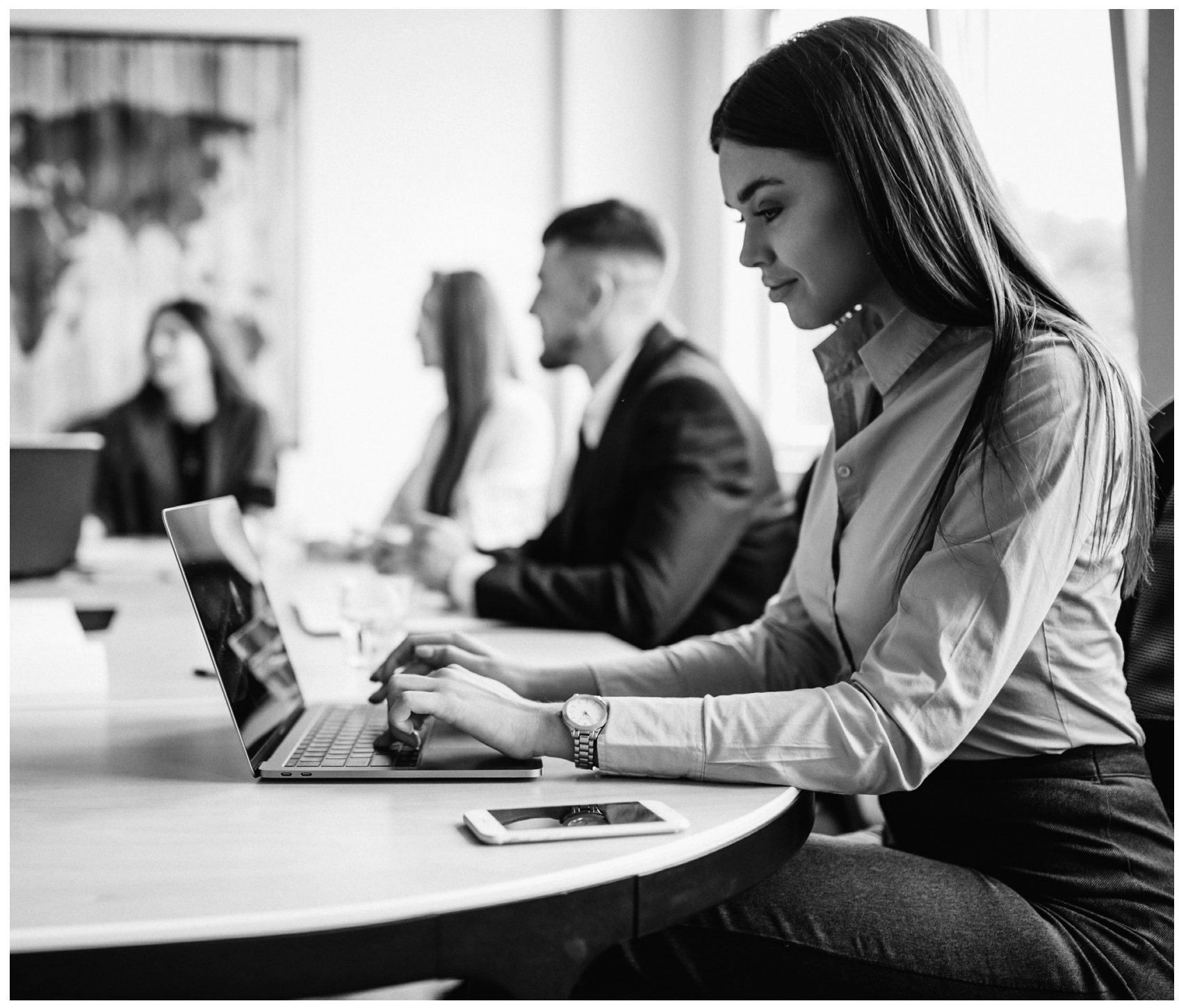




\title{
El escepticismo científico en la construcción de la información financiera: Estado del conocimiento ${ }^{1}$ Scientific skepticism in the construction of financial information: State of the art
}

\author{
Luz María Solano Ruíz ${ }^{2}$
}

Artículo recibido en octubre 18 de 2018; artículo aceptado en enero 30 de 2019.

Este artículo puede compartirse bajo la Licencia Creative Commons Atribución-NoComercial-Compartirlgual 4.0 Internacional

y se referencia usando el siguiente formato: Solano, L. (2019). El escepticismo científico en la construcción

de la información financiera: Estado del conocimiento. I+D Revista de Investigaciones, 14 (2), 7-16.

DOI: https://doi.org/10.33304/revinv.v14n2-2019001

\begin{abstract}
Resumen
Este documento presenta una investigación empírica, desde el punto de vista filosófico, frente a hechos que atentan contra la conducta ética profesional y el escepticismo en la construcción de la información financiera. La observancia del comportamiento moral y del principio de independencia del contador público, como depositario de la confianza pública, ha sido cuestionada a lo largo de la historia. Ello debido a escándalos financieros y quiebras millonarias, en las que estos profesionales no han cumplido con su deber de velar por los intereses económicos de quienes han depositado en ellos su confianza, pese a regirse por códigos de ética. Esto lleva a que las organizaciones de contadores, la sociedad, las empresas y las instituciones educativas sumen esfuerzos, con el fin de potenciar la formación que desde el seno familiar viene adquiriendo el profesional. Este dilema lleva a cuestionarse la siguiente pregunta: ¿cómo enfrentar las amenazas que los cambios del mundo globalizado y de los negocios implican sobre el escepticismo del contador público? Esto es, los cambios sobre sus principios éticos y de independencia, que distorsionan y comprometen su ejercicio profesional en la construcción de la información.
\end{abstract}

Palabras clave: Código de ética, escepticismo, contador público, moral, ética.

\begin{abstract}
This study presents an empirical investigation of facts that attempt against professional ethical conduct and skepticism in the construction of financial information, from the philosophical point of view. The observation of the moral conduct and the principle of independence of the public accountant, as depositaries of the public trust, has been questioned throughout history. This is due to financial scandals and millionaire bankruptcies, in which these professionals have not fulfilled their duty to watch over the economic interests of those who have placed their trust in them, despite being governed by Codes of Ethics. This leads the organizations of accountants, society, companies, and educational institutions to join forces, in order to enhance the training that the professional has
\end{abstract}

1. Artículo de revisión, enfoque paradigmático, aspecto analítico-interpretativo, modalidad de investigación documental-analítica, resultado de un proyecto de investigación culminado, perteneciente al área de ciencias socioeconómicas, subárea contable. Desarrollado en el grupo de investigación SERCONT. Sin financiación por parte de la universidad. Fecha de inicio: enero de 2018. Fecha de terminación: abril de 2018.

2. Integrante del Grupo de Investigación SERCONT, de las Unidades Tecnológicas de Santander, Bucaramanga (Colombia). Dirección: avenida los Estudiantes 9-82. PBX: 6917700. ORCID: https://orcid.org/0000-0003-1692-1720. Correo electrónico: peticiones@correo.uts.edu.co. 
acquired within the family. This dilemma leads us to ask the following question: How to face the threats that the changes of the globalized world and of business imply on the public accountant's skepticism? Their ethical and independence principles, distorting and engaging their professional practice in the construction of information.

Keywords: Code of ethics, skepticism, public accountant, moral, ethics.

\section{Introducción}

El articulo presenta una investigación basada en los principios filosóficos de la ética y el escepticismo profesional, así como en las posturas de algunos de sus principales pensadores, las reflexiones alrededor del código de ética, la valoración crítica acerca de la conducta que desarrolla el profesional en contaduría pública y la influencia de sus actitudes frente a la sociedad. Asimismo, se analiza el escepticismo científico del profesional frente a la construcción de la información financiera.

\section{Metodología}

Las técnicas utilizadas para el rastreo de antecedentes son la revisión bibliográfica y el análisis de contenido teórico. La investigación se elabora bajo el enfoque paradigmático, dentro del aspecto analítico interpretativo. La modalidad de la investigación es documental, del tipo analítico. El estudio corresponde al tipo explicativo, descriptivo, transversal y no experimental.

Por tratarse de un estudio basado en principios filosóficos, se tomaron como referentes algunos filósofos que han sentado su postura con respecto a la ética. El presente estudio se basó en información bibliográfica histórica existente hasta 2018.

Para llevar a cabo el estudio, y por tratarse de un estado del conocimiento, se inició con la búsqueda de publicaciones de investigaciones en revistas indexadas, libros, congresos y memorias de eventos académicos que incluían documentación histórica; una documentación que va desde la antigua Grecia hasta su incidencia en el marco de las normas internacionales de contabilidad.

\section{Fundamentos éticos del escepticismo profesional}

La ética es una disciplina de la filosofía que cuestiona la conducta humana frente a determinadas situaciones en las que el individuo valora el mundo desde el punto de vista de lo que es bueno o es malo (Rubio \& Mojica, 2017). A través del tiempo, la ética ha sido un tema tratado por los investigadores de diversas disciplinas, especialmente la filosofía, la psicología y la sociología. En este marco, se ha atendido siempre a la interacción entre el individuo y la comunidad.
Las categorías de la ética distinguen entre posiciones optimistas y pesimistas. Asimismo, existen otras posiciones, como las racionalistas, empiristas y escépticas o dogmáticas. A continuación, una breve reseña de los principales filósofos y sus posturas sobre la ética.

\section{Sócrates (c. 470 -c. 399 a. C.). Racionalista}

Fundador de la filosofía moral o axiología, partidario de la superioridad de la discusión sobre la escritura, pasó su vida de adulto en las plazas públicas de Atenas. Usaba el método conocido como mayéutica. A todo aquel que quisiera escuchar su postura le respondía por medio de preguntas, con el fin de que este, por sí mismo, descubriera sus verdades. Su lógica hizo énfasis en la discusión racional y la búsqueda de definiciones generales. Esto se reflejó después en la filosofía de Platón y Aristóteles, quienes influyeron en el posterior pensamiento especulativo occidental.

\section{Platón (c. 425-c. 347 a. C.) Idealista}

Su filosofía se centra en la teoría de las formas o de las ideas. Desde esta perspectiva, se entienden sus ideas sobre el conocimiento, la teoría ética y la psicología, así como sus concepciones sobre el Estado y el arte.

\section{Aristóteles (384-322 a. C.) Eudemonista}

Desde una perspectiva ética, consideraba que la libertad de elección del individuo hacía imposible un análisis preciso y completo de las cuestiones humanas. De esta forma, las "ciencias prácticas", como la política o la ética, se llamaban ciencias solo por cortesía y analogía. Los seres naturales se orientan hacia el desarrollo pleno de sus potencialidades; $y$ el bien es igual a la perfección de un ser o desarrollo de sus capacidades. Lo anterior desemboca en el interrogante sobre cuál es la funcionalidad propia del hombre. Si existe más de un bien propio del hombre, cuál sería el más alto y perfecto que podría alcanzar.

\section{San Agustín de Hipona (354-430). Moralista}

La ética cristiana debe afrontar el problema de la existencia del mal y la libertad humana. A partir de este problema, surgen varios cuestionamientos. Uno de ellos alude a Dios. Dado que Dios es un ser omnipotente, ¿cómo es posible que permita la existencia del mal en 
el mundo?; ¿no pudo acaso crear un mundo donde no existiera el mal? Esto lo responde San Agustín refiriéndose a Plotino. Dios no puede crear el mal, porque el mal no es ser, sino una privación, una carencia de ser que afecta a los seres finitos y creados.

\section{Santo Tomas de Aquino (1225-1274). Teocéntrica}

Apoyado en el concepto de felicidad de Aristóteles, en cuanto fuente de salvación del hombre, analiza los medios para alcanzarla. Estos medios pueden ser externos, que hacen referencia a los actos humanos; internos, que se representan en la ley natural que sirve de guía al hombre para adquirir hábitos y virtudes; y sobrenaturales, alusivos a la "gracia divina" con la que Dios ayuda al hombre a alcanzar su fin.

\section{René Descartes (1596-1650). Intelectualista}

Para este filósofo, el intelectualismo se refleja en el deseo de aprender a distinguir lo verdadero de lo falso, con el fin de ver claras las acciones y caminar con seguridad por la vida. Para Descartes, la libertad se refiere a la decisión de poder elegir lo que es bueno y verdadero. Es aquí donde se define como un intelectualista, ya que considera que la libertad no se basa solo en la indiferencia, sino en el sometimiento positivo de la voluntad al entendimiento.

\section{David Hume (1711-1776). Emotivista moral}

En este autor, el análisis de la ética está ligado al de la política, mas con la pretensión de hacerlos independientes del fundamento metafísico. Se basa en la observación y la experiencia. La razón no puede ser el fundamento de los juicios morales, porque no define nuestro comportamiento ni lo impide. Para él, el conocimiento racional es de dos tipos: de relaciones entre ideas o de hechos. El conocimiento referido a relaciones entre ideas, como la lógica y la matemática, es de gran utilidad; pero no hace que el individuo se incline por las acciones virtuosas y justas. El conocimiento de los hechos, por su parte, solo los muestra, pero permite determinar si son buenos o malos. Para Hume (tal como lo argumenta Rousseau), el fundamento de estos juicios está en el interior del hombre, en su corazón, de donde brotan los sentimientos de aprobación y desaprobación.

\section{De la ética y el escepticismo}

Dentro de la comunidad científica, el escéptico evalúa toda información con base en su falsabilidad. Es decir, no acepta afirmaciones de una tesis o teoría cuyo basamento esté en la fe, las anécdotas, las historias o cualquier fuente no veraz. En definitiva, es una postura que niega que el ser humano pueda conocer (Gutiérrez Rueda, 2003).

El escéptico basa sus críticas en afirmaciones que, a su modo de ver, son dudosas ante la ciencia. El principio consiste en que sea el individuo quien pueda llegar a una conclusión, apoyado en pruebas demostrables y sin dejarse influenciar por otros agentes escépticos. De este modo, forma parte del método científico. Desde la ciencia, juzga las teorías con criterios como la falsabilidad ${ }^{3}$, la repetitividad ${ }^{4}$ y la navaja de Ockham ${ }^{5}$. A su vez, otros términos han surgido a raíz de esta postura. Uno de ellos se conoce como pseudoescepticismo, una postura crítica en la que el científico niega sin aportar pruebas.

\section{Historia del escepticismo}

En la antigua Grecia, el escepticismo se apoyaba en una analogía médica, como si fuese una cura para purgar la vida humana de cualquier compromiso cognitivo y de cualquier creencia (Alcalá, 2005).

Se la reconoce no como una escuela de la filosofía, sino como una actitud intrínsecamente establecida en el acto de pensar. Se trata de una disposición, no de una doctrina. De este modo, reclamar una figura como la de "maestro" sería una contradicción.

Se han llevado a cabo investigaciones para determinar el origen del escepticismo. De estas, se ha concluido que no existe un creador único, sino diversos filósofos que fueron acuñando este término (Gutierrez Rueda, 2003).

Con el pirronismo se tiende a usar el método o estilo de filosofar. Allí se trazan oposiciones entre tesis y juicios. La oposición de juicios consiste en una habilidad para balancear juicios antitéticos de un mismo estado de cosas (Larriguet, 2015).

La era helenística ha sido la base en que se han acuñado las teorías posmodernas, por su relativismo y propensión al oportunismo ideológico (Mansilla, 2004).

\footnotetext{
3. Principio epistemológico que propone una demarcación entre las teorías científicas y las que no lo son. Para tal fin, se basa en la posibilidad de falsar las teorías científicas.

4. Dentro del campo científico, es la capacidad que tiene una teoría de ser reproducida por otros.

5. Se atribuye al monje franciscano y filósofo Guillermo de Ockham. Es un principio de razonamiento formulado al final de la Edad Media. También se lo conoce como principio de economía, principio de parsimonia o de simplicidad.
} 


\section{Pirrón de Elis}

Es el único escéptico antiguo a quien los doxógrafos ${ }^{6}$ atribuyen una "vida sin creencias". Es pionero del escepticismo. Su actitud y talento están lejos de la expectativa de vida convencional de todos los escépticos. Para Pirrón, lo importante es vivir sin creencias, sin aceptar algún tipo de filosofía. Es esto lo que conduce a la felicidad (Diccionario filosófico, 1984).

\section{Timón de Fliunte}

Fue discípulo de Pirrón, heredó sus doctrinas filosóficas y fue su portavoz. Siguió a Pirrón en casi todas sus posturas. Según Diógenes Laercio (IX, 109-111), Timón reunió una buena fortuna ejercitando su filosofía y la oratoria, en Calcedonia. No obstante, introduce también una crítica acerca del autor. Según Antígonos de Caristo, fue más dado a la bebida que a la aplicación de la filosofía.

\section{Diógenes Laercio}

No se lo reconoce como perteneciente al escepticismo. Aun cuando recorrió los caminos de Pirrón, no lo tomó como modelo en todas las cosas. No se resignó a la pobreza que caracterizaba a su maestro; no tuvo esa dignidad que conquistó a los ciudadanos.

\section{Cicerón}

No se lo reconoce como perteneciente al escepticismo. De no haber sobrevivido en distintos pasajes en los que se habla de Pirrón, no se habría vislumbrado que hubiese sido un escéptico. En su obra, no se encuentra ninguna alusión a la duda escéptica o la suspensión del juicio. Esto no parece guardar una relación directa con Pirrón. Por el contrario, se lo relaciona más con Arcesilao.

Se lo ubica en el punto de vista académico, no en el de la doctrina propiamente dicha. La academia pasó del escepticismo al eclecticismo de Filón de Larissa y Antíoco de Ascalón. Se tomaban como base algunas observaciones de Cicerón en su De natura deorum, a fin de refutar la obra de San Agustín Contra los académicos. De allí se pasó a la escuela de los escépticos pirrónicos, que se asoció eventualmente con la Escuela Metódica de Medicina en Alejandría (Zamitiz Gamboa, 1994).

En sus textos, Cicerón afirma que las teorías de Pirrón se perdieron por falta de sucesores. Cuando menciona a los

6. Rama de la literatura que comprende obras dedicadas a recoger puntos de vista de filósofos y científicos del pasado sobre la filosofía. pirrónicos, deja ver, sin embargo, su afinidad con otras escuelas, como la de los eritreos o la de los megáricos.

\section{Sexto Empírico}

Pertenece a la corriente del pirronismo. Hacia el 200, elabora una síntesis de este movimiento filosófico, con el objeto de reconstruirlo desde sus fundadores. En este rastreo, Sexto busca elementos característicos del escepticismo. Encuentra que Pirrón pertenece a un grupo de autores que han conformado el escepticismo. Además, Pirrón sería, en este sentido, su principal exponente.

Como el escepticismo no es una doctrina, sino una actividad, su origen no se le puede atribuir a un único creador. Sin embargo, se le atribuye a Pirrón un cambio en el escepticismo: el de conseguir que la actitud escéptica fuese independiente de cualquier concepción filosófica.

De este modo, no se considera a Pirrón como un maestro iniciador de este movimiento filosófico. En su lugar, se considera que encarna un nuevo uso de la filosofía que se ocupa de las creencias, de su racionalidad y de su necesidad. Esto es, ya no solamente de las afirmaciones del conocimiento (Filosofía griega, 2000).

\section{La afasia y la ataraxia del escepticismo}

La ataraxia es una disposición del ánimo propuesta por los epicúreos, estoicos y escépticos. Gracias a ella, el sujeto, una vez que disminuye la intensidad de pasiones y deseos que puedan alterar su equilibrio mental y corporal, e incrementa su fortaleza frente a la adversidad, alcanza el equilibrio y finalmente la felicidad. Se trata de tranquilidad, serenidad e imperturbabilidad, en relación con el alma, la razón y los sentimientos.

Para los escépticos, se concibe como una corriente filosófica basada en la duda el no creer en una verdad objetiva. Ello, por cuanto todo es subjetivo, en función del sujeto que se estudia, no del objeto estudiado

Alcalá (2005) expresa lo siguiente:

La afasia está ligada, en la lengua griega, al estado de emoción que anuda nuestra garganta e impide la palabra. En Pirrón adquiere un significado especial y técnico, porque no se trata de "quedar sin palabra", sino de "no tener nada que decir sobre las cosas". El uso del vocablo se hace en forma deliberada, pues el hombre no está intranquilo, turbado, y ello le hace perder la palabra, sino que es la falta de perturbación, la tranquilidad a la que llega, la 
causa de la aparición de la afasia; la suspensión de la palabra lleva a la ataraxia.

\section{El escepticismo en el marco internacional}

Viloria (2016) refiere que el escepticismo profesional del contador público encuentra su normatividad en el Marco Internacional de Referencia de Aseguramiento, de las Normas Internacionales de Aseguramiento y Auditoría (NIAA). Allí se describe al escepticismo profesional de la siguiente manera:

Una actitud de escepticismo profesional significa que el contador lleva a cabo una evaluación crítica, con una mente inquisitiva, sobre la validez de la evidencia obtenida, y está alerta a la evidencia que contradice o pone en tela de juicio la confiabilidad de los documentos o representaciones de la parte responsable.

Anota Viloria (2016) que los organismos emisores de las normas contables y de auditoría comparten la importancia del escepticismo profesional. Añade que son diversas las publicaciones sobre el tema. Tales organismos emisores son el IFAC (2011), el Financial Report Council (2012), e investigadores como Hurtt, Eining y Plumlee (2003), Nelson (2009) y Verwey (2009).

\section{Reflexiones acerca del código de ética}

Para reflexionar sobre el código de ética, se debe aludir antes al origen del término 'ética' para discernir sobre la importancia y justificación de los códigos de ética.

La ética es una rama de la filosofía que se dedica a los asuntos morales. La palabra 'ética' proviene del latín ethǐcus, que a su vez proviene del griego antiguo $\dot{\eta} \theta$ ıкó (êthicos), derivada de êthos, que significa 'carácter' o 'perteneciente al carácter' (Enciclopedia de conceptos, 2018; Serrano, 2015).

La ética se relaciona así con el estudio de la moral y de la acción humana. Una sentencia ética es una declaración moral que elabora afirmaciones y define, entre otros aspectos, lo que es bueno, malo, obligatorio o permitido, en lo referente a una acción o a una decisión (Serrano, 2015).

Esta definición de 'ética' señala que su objeto de estudio es la moral, como la característica que rige la vida del hombre en la sociedad. La moral es una creación del hombre que permite identificar si los actos realizados son buenos o malos. A su vez, lo que se debe y lo que no se debe hacer, lo prohibido y lo permitido, lo lícito y lo ilícito.
Desde el punto de vista de la autora, la moral es la base para la conformación de un código de ética. Y este, a su vez, no es otra cosa que un compendio de normas que fijan el comportamiento de los individuos dentro de un marco de referencia, grupo social o profesional específico.

Diversos autores han expresado sus ideas acerca de lo que representan la moral y el código de ética.

Galán (1999) expresa el concepto de 'ética profesional':

El ethos de la profesión es el conjunto de principios, actitudes, virtudes y normas éticas específicas y maneras de juzgar las conductas éticas que caracterizan a un determinado grupo de profesionales. La ética profesional debe concentrar su atención en el tema de los valores y los principios a realizar en las profesiones. La ética se mueve siempre en el campo de la conciencia individual, desde un plano colectivo.

A su vez, este autor pone en relación la ética profesional con el concepto de 'código de ética':

La ética profesional suele plasmarse en códigos de ética profesional. Un código de ética profesional es una organización sistemática de cuáles son las responsabilidades morales que provienen del rol social del profesional y de cuáles son las expectativas que las personas tienen derecho a exigir con relación a él.

En este sentido, las profesiones se regulan por normas técnicas, jurídicas y morales. Esto lleva a que cada organismo regulador diseñe su propio código de ética, de acuerdo con su dinámica profesional.

En este contexto, cobra relevancia la Federación Internacional de Contadores (IFAC). Esta organización representa en el ámbito mundial a los contadores profesionales. Mediante un código de ética, promueve la estandarización y conducta, para orientar el ejercicio de la profesión del contador público.

Es así como cada país estructura su código de ética en función de sus leyes, su situación económica, su política y su dinámica profesional. Así, se normatiza lo que es lícito o permitido dentro de la profesión. Cada país tiene un código de ética diferente al de los demás países, pero todos bajo el mismo eje primordial de moral y ética.

A su vez, desde su concepción de la ética, la IFAC promueve una profesión contable con estándares 
armonizados en el ámbito mundial, recomendando a los países que hayan adoptado normas internacionales de contabilidad (NIC) la aplicación, en todas sus partes, del código de ética. Se entiende el código, entonces, como un cooperante en la aplicación de estas normas (Zaá Méndez, 2013a).

En su artículo sobre la pertinencia de la adopción plena del código de ética de la IFAC, Zaá Méndez (2013a) hace una reflexión sobre la adopción del código IFAC desde una dimensión científico-profesional, filosófica y cuantitativa. Hace allí referencia a su adopción en diversos países, entre ellos Venezuela.

Documenta Zaá Méndez (2013a) que la adopción se estableció por medio de un plan que comprendió cinco áreas: las Normas Internacionales de Información Financiera, las Normas de Auditoría, las Normas Internacionales de Auditoría Interna, las Normas Internacionales de Contabilidad para el Sector Público y el Código de Ética de la IFAC.

Este tema se discutió en el Congreso de Contaduría Pública de Puerto la Cruz (Venezuela) en 2008. Allí se decidió adoptarlo plenamente, a pesar de que tuvo varios contadores opositores, quienes lo consideraron pertinente, ya que, según ellos, debía adoptarse parcialmente atendiendo la realidad venezolana, de acuerdo con las leyes, el contexto económico y social del país.

Para el caso colombiano, la Junta Central de Contadores, mediante la Ley 43 de 1990, normatizó el Código de Ética del Contador Público. Mediante la Ley 1314 de 2009, se adoptaron las Normas contables NIC y NIIF, así como las normas de auditoría NAI y NIA. En este proceso de internacionalización de la contabilidad, se establece el cumplimiento del Código de Ética y la conducta internacional de la IFAC como base normativa mundial en la presentación de los informes financieros. Así como había ocurrido en Venezuela, en Colombia también se presentaron oponentes a este proceso de adopción. Según ellos, era preciso tener en cuenta la situación particular del país en materias económica y política

Las situaciones de estos dos países hermanos llevan a reflexionar si es pertinente la adopción plena, en esta parte del continente, del Código de Ética de la IFAC. Esto es, la pertinencia del Código como complemento necesario en el proceso de adopción de las Normas Internacionales de Información Financiera

Esta reflexión ha sido motivo de discusión en los diversos países involucrados. Esto por las variables de las medidas económicas y políticas de cada país. Es asimismo fuente de diversas investigaciones que buscan determinar la pertinencia de un código de ética que es ajeno (el de la IFAC) a los contadores públicos en cada país. Estas investigaciones pretenden detectar los vacíos del citado código frente a la adopción de normas internacionales.

\section{Valoración crítica de la conducta del profesional de contaduría pública y su influencia en la sociedad}

Para hablar de la conducta del profesional de contaduría, es fundamental conocer la norma respectiva de cada país. Se analiza a continuación la normativa en Colombia.

La contaduría pública es una profesión que tiene como fin satisfacer necesidades de la sociedad, mediante la medición, evaluación, ordenamiento, análisis e interpretación de la información financiera de las empresas o los individuos y la preparación de informes sobre la correspondiente situación financiera, sobre los cuales se basan las decisiones de los empresarios, inversionistas, acreedores, demás terceros interesados y el Estado acerca del futuro de dichos entes económicos. El contador público como depositario de la confianza pública da fe pública cuando con su firma y número de tarjeta profesional suscribe un documento en que certifique sobre determinados hechos económicos. Esta certificación hará parte integral de lo examinado (Ley 43 de 1990, art. 35, inciso 2, 1990).

El artículo de la citada ley menciona al contador púbico como depositario de la confianza pública inmerso en la ética y la moral. A propósito de la moral, se lee en el citado artículo:

El contador público, sea en la actividad pública o privada, es un factor de activa y directa intervención en la vida de los organismos públicos y privados. Su obligación es velar por los intereses económicos de la comunidad, entendiéndose por esta no solamente a las personas naturales o jurídicas vinculadas directamente a la empresa, sino a la sociedad en general y naturalmente al Estado. La conciencia moral, la aptitud profesional y la independencia mental constituyen su esencia espiritual. El ejercicio de la contaduría pública implica una función social especialmente a través de la fe pública que se otorga en beneficio del orden y la seguridad en las relaciones económicas entre el Estado y los particulares, o de estos entre sí (Ley 43 de 1990, art. 35, inciso 2, 1990).

De acuerdo con lo anterior, la sociedad toma decisiones futuras concernientes a los entes económicos que se 
basan en las atestaciones de los contadores. Es tarea del contador la de prestar apoyo a los tomadores de decisiones, por medio del cálculo de datos para la proyección de flujos de caja, indicadores financieros, datos estadísticos basados en estados financieros $y$, en general, todo aquello que permite visionar el futuro económico y financiero de las empresas.

La confianza pública como un hecho y la fe pública como efecto jurídico atribuido a las manifestaciones del contador se ven afectadas ante los escándalos financieros suscitados en empresas multinacionales. Casos como los de Parmalat, World Co. y Xerox, entre otros, hacen necesario que los gremios aúnen esfuerzos, no solo en lo que a adopción de normas internacionales de contabilidad se refiere, sino en lo que tiene que ver con la conducta ética y moral que se debe observar, no solo en el cumplimiento de un código de ética, sino también desde la asignatura de ética como eje transversal del currículo académico de las universidades, como un complemento a la información recibida en los entornos familiares.

La confianza púbica adquirida en el ejercicio de la profesión debe mantenerse, en función de los compromisos de integridad, objetividad y transparencia. Es este un sello personal del contador público, un sello sin el cual la profesión marcharía con paso firme hacia su destrucción.

En torno a la ética profesional, hay diversas posturas, manifestaciones y observancias. Esto genera un campo fértil de estudios e investigaciones tendiente a la mejora del régimen ético actual. La ética profesional se ha convertido en un desafío para la contaduría en el ámbito internacional.

\section{La construcción de la información financiera}

La información financiera es aquella que los departamentos de contabilidad producen de forma cuantitativa. Se expresa en cifras económicas, mediante la unidad monetaria del país de origen, y refleja las cifras de las organizaciones, tanto de sus derechos como de sus obligaciones, en un periodo de tiempo determinado.

Esta información se presenta por medio de recursos como los estados financieros, los flujos de efectivo y el estado de resultados. Esto con el fin de que los interesados en dichas organizaciones conozcan su

7. Stakeholder o parte interesada hace referencia a personas, organizaciones, empresas y, en general, a quien tiene interés en una organización. Las personas interesadas pueden ser de diversa índole: desempeño y se sirvan de esta información para los fines que les sean útiles. De igual forma, se usa para la toma de decisiones de grupos interesados o stakeholders ${ }^{7}$.

Para su elaboración y presentación, se usan las Normas Internacionales de Información Financiera (NIIF). Estas normas se basan en los ocho postulados que establecen el actuar de los sistemas de información financiera. De entre ellas, los cinco principales son los siguientes:

- Sustancia económica: La esencia del emisor de la información es la que le permite identificar los efectos que le puedan ocasionar las transacciones, tanto internas como externas, que se realicen a su alrededor. Por ejemplo, una empresa vende (transfiere la propiedad) una maquinaria a otra empresa, y legalmente se realiza la transacción documentada; pero, bajo un convenio entre las dos empresas, la primera continúa usándola y/o disfrutando de sus beneficios económicos. En este evento, aun cuando la venta se realizó efectivamente, de modo que se ha dado el hecho jurídico, se estaría frente al caso de no representar efectivamente las transacciones de venta llevadas a cabo.

- Entidad económica: Es la agrupación de recursos materiales, financieros y humanos puestos en función del desarrollo de una actividad económica dada.

- Negocio en marcha: Se refiere a la actividad continuada de una empresa, a menos que los estados financieros indiquen lo contrario.

- Devengación contable: Identifica el momento en el cual se realiza una transacción de una entidad. Esta transacción debe registrarse contablemente en ese mismo instante.

- Asociación entre costos y gastos: Hace referencia a la correspondencia o identificación que debe existir entre los gastos y los costos frente a los ingresos, en un mismo periodo que además sea independiente del momento en que se realicen.

\section{Escepticismo científico en la construcción de la información financiera}

De acuerdo con Zaá Méndez (2013a), el mundo globalizado y su dinámica propia, con la complejidad que conllevan los hechos y transacciones económicas, desembocan en amenazas al Principio de Independencia

clientes, accionistas, trabajadores, proveedores, asociaciones, ligas y en general organizaciones civiles o públicas que se encuentren vinculadas (Freeman y Moutchnik, 2013). 
Profesional del Contador Público. Este principio se ve afectado con frecuencia por una serie de factores de distinta naturaleza que distorsionan y comprometen el ejercicio profesional del contador en el desarrollo de trabajos de atestiguamiento.

El principio de independencia es uno de los postulados contemplados en el ejercicio profesional del contador público. Se incluye además en el código de ética, sin el cual no se podría dar lugar a la emisión de opiniones, certificaciones y fe pública como garante de la transparencia contenida en los estados financieros, y sobre los cuales los usuarios puedan tomar decisiones (Viloria, 2013). De lo anterior, se colige lo siguiente: para que exista independencia, debe existir ética, y esta va estrechamente ligada con el escepticismo a la hora de construir la información financiera.

Considera Zaá Méndez (2013a) que, en lugar de reescribir el Principio de Independencia del Contador Público, es imprescindible comprometer al profesional en su observancia mediante el reforzamiento en la definición del principio y los basamentos sobre los cuales descansa su esencia.

Los códigos de ética adoptados en cada país se refieren a la práctica de esta como la base del principio de independencia. Afirma Zaá Méndez (2013b) que los trabajos efectuados por los profesionales contables están constantemente bajo amenazas que ponen en duda la observancia objetiva de los principios de ética y escepticismo bajo los cuales debe desarrollar su trabajo.

Es así como estas amenazas están asociadas con la naturaleza y tipo de labor encomendada. Para el caso de la construcción de información financiera, el contador debe proveer salvaguardas, para hacer frente a ellas y garantizar el cumplimiento de los principios previstos en el código de ética.

Constituyen amenazas los casos de interés personal, de revisión, de mediación de familiaridad y de intimidación que deben eliminarse, o, de lo contrario, al menos reducirse, por medio de la aplicación de las salvaguardas creadas por la legislación o la profesión (Zaá Méndez, 2013b).

A fin de enfrentar estas amenazas, propone Zaá Méndez (2013b) identificar, en primer lugar, las amenazas más representativas presentes en el trabajo; $y$ en segundo lugar, cumplir cabalmente los principios éticos y de escepticismo previstos, apoyándose en un marco referencial conceptual desarrollado en el código.

\section{Discusión}

En los últimos años, los avances de la contaduría pública como profesión liberal han sido una respuesta a la satisfacción de las necesidades de la sociedad que requiere información actualizada y oportuna, para surgir en una economía globalizada y dentro de un contexto normativo ético y moral, de cuyo estricto cumplimiento depende la buena imagen de la profesión.

La ética y el escepticismo profesional contemplados en los códigos de ética permiten que el contador público pueda llegar a conclusiones basado en pruebas demostrables, sin encontrarse influenciado por agentes externos que sesguen la construcción de la información financiera.

La profesión de contador público tiene una función social, a través de la fe pública. El dictamen, la certificación y finalmente la firma que el contador público emite sobre un estado financiero comprueban que la información allí contenida se ha ajustado a las normas legales vigentes y estatutarias. La firma certifica que el contador ha obtenido la información necesaria para soportar su concepto; un concepto sobre el cual los usuarios podrán tomar decisiones confiables que afectan el futuro de los entes económicos que el contador público ha aseverado. Todo lo anterior redunda en la confianza del público ante una opinión fundamentada en la moral y el escepticismo ético.

\section{Agradecimientos}

Agradecimientos especiales al Ph. D. Jose Rafael Zaá Méndez, quien, en calidad de tutor del Doctorado en Ciencias Contables, contribuyó en la realización de la presente investigación.

\section{Referencias}

Alcalá, R. R. (2005). El escepticismo antiguo: Pirrón de Elis y la indiferencia como terapia de la filosofía. Daimon Revista Internacional de Filosofía, (36), 33-52.

Diccionario filosófico. (1984). Pirrón de Elis. Recuperado de http://www.filosofia.org/enc/ros/pir.htm

Enciclopedia de conceptos. (2018). "Ética." Recuperado de https://concepto.de/etica/

Filosofía griega. (2000). Sexto Empírico. Recuperado de http://www.cinicos.com/sexto.htm

Freeman, E., \& Moutchnik, A. (2013). Stakeholder management and CSR: questions and answers. uwf UmweltWirtschaftsForum, 21(1-2), 5-9.

Galán, J. P. (1999). Ética, profesión y medios: la apuesta por la libertad en el éxtasis de la comunicación. 
Universidad Iberoamericana.

Gutiérrez Rueda, C. (2003). El escepticismo filosófico antiguo y el problema de la justificacion epistemológica. Elementos: Ciencia y Cultura, 10(51), 43-51.

Hurtt, K., Eining, M., \& Plumlee, D. (2003). Professional Skepticism: A Model with Implications for Research, Practice and Education. (No. Working paper). Wisconsin: University of Wisconsin. Recuperado de www.business. utah.edu

Larriguet, G. (2015). Una revisión crítica de Dudas filosóficas. Ensayos sobre escepticismo antiguo, moderno y contemporáneo. Diánoia, 60(75) 129-139.

Mansilla, H. (05 de 2004). El escepticismo clasico y moderno coo precursores de las teorias postmodernistas. Revista de filosofia, 22(47) 51-64.

Nelson, M. W. (2009). A model and literature review of professional skepticism in auditing. Auditing: A Journal of Practice \& Theory, 28(2), 1-34.

Rubio, J. E. H., \&Mojica, K.Y.S. (2017). La transdiciplinariedad de la ética en las ingenierías. I+ D Revista de Investigaciones, 9(1), 70-81.

Serrano, S. E. G. (2015). La relación entre el habitar-ethos y la ética. Antropología educativa. I+ D Revista de Investigaciones, 6(2), 6-18.

Verwey, I. G. F. (2009). The differences between auditors and forensic accountants with respect to their ability to identify effective additional procedures to mitigate identified fraud risks (No. NRI09-23). Nyenrode Business Universiteit.). Recuperado de https://www. nyenrode.nl/research

Viloria, N. (2013). El escepticismo profesional: Estrategias de aula para los estudiantes de contaduría pública. Actualidad Contable Faces, 16(27). Recuperado de https://www.redalyc.org/html/257/25728957007/

Viloria, N. (2016). Estrategias de reforzamiento de escepticismo profesional para los contadores públicos en actividad de auditoría., 19(33). Actualidad Contable Faces, 19(33), 112-134. Recuperado de https://www.redalyc.org/html/257/25746579007/

Zaá Méndez, J. R. (2013a). Pertinencia de la adopcion plena del codigo de Ética de la Federacion Iternacional de Contadores (IFAC) como instrumento regulador de la profesión contable. Valle de la Pascua, Estado guárico, Venezuela.

Zaá Méndez, J. R. (2013b). Amenazas y salvaguardas del principio de independencia en trabajos de atestiguamiento según el Marco de Referencia Normativo que regula la práctica profesional del Contador Público Venezolano. Recuperado en 5 Jun., 2018

Zamitiz Gamboa, H. (1994). Aspectos históricoconceptuales del escepticismo: una aproximación al estudio del escepticismo en la política. Revista Mexicana de Ciencias Políticas y Sociales, 39(157), 159-179. 